\title{
ON THE POROSITY OF THE ROCKS OF THE KARROO SYSTEM IN SOUTH AFRICA.
}

\author{
By Alex. L. Du Toit, D.Sc., F.G.S. \\ (Published with the permission of the Hon. the Minister for Mines and \\ Industries.)
}

(Received April 7, 1914. Read April 15, 1914.)

In a paper read last year before the South African Society of Civil Engineers * the author stated that the strata in South Africa taken as a whole possessed a rather low degree of porosity, and that this was especially applicable to the rocks of the Karroo System, covering, as they do, fully one-half of the Union of South Africa.

It was pointed out moreover, that, as the result of weathering, any estimate of the pore-space of a rock as based upon specimens taken from the outcrop of the stratum, as is generally the case, is in excess of its true value as found when dealing with the fresh and unaltered material.

For these and for other reasons the Karroo region was not anticipated to be one capable of furnishing strong artesian supplies as has not uncommonly been thought.

Since, however, these statements were subjected to criticism, a large number of determinations were made upon rocks from the Karroo System of the Cape Province, a number of figures obtained in the Geological Survey Laboratory, Pretoria, upon certain Karroo sandstones of the Transvaal + being also included in the list.

The results, tabulated below, bear out in the fullest manner the author's contentions; time did not permit of an exhaustive investigation of this rather wide and important subject, for several interesting dependent problems emerged in the course of the tests for fuller inquiry and treatment at some future period.

The specimens experimented upon consisted for the most part of

* Min. of Proc. S.A. Soc. Civil Engineers, vol. xi., p. 8. Cape Town, 1913.

† Annual Report Geological Survey of S. Africa for 1910, p. 105, Pretoria. 
sections of core from diamond drill borings put down by the Public Works Department under the late Cape Government, samples duly labelled and accompanied by full records of the strata passed through being preserved in the Geological Survey Office, Cape Town. The cylindrical specimens, varying in weight from about 100 to 300 grams, were dried, weighed, and soaked in water until no further absorption took place. The smaller-sized samples were preferred because of the greater rapidity with which they absorbed water; this was especially so in the case of very soft shales and mudstones, the cylinders of which frequently will not stand soaking for more than a few days' time without breaking up. Indeed, the only accurate procedure with the soft red and purple mudstones would be to work in the field upon wet cores just extracted from the borehole. Since such friable argillaceous rocks possess only a low degree of porosity, few determinations were made upon them.

With certain exceptions, which were instituted for purposes of comparison, all the samples were from strata cut below a depth of 25 feet from the surface, while the majority came from between 50 and 150 feet; in this way the values obtained must approach more closely to those under the conditions actually existing in boreholes and wells. The increased value of the porosity dependent upon surface alterations will be discussed later on.

Care was taken in the selection of the core samples that these did not come from layers directly over or underlain by dolerite, sheets of which are prevalent throughout the Karroo except on its extreme southern margin and in the south of the Transvaal. Indeed, not uncommonly the soft shales and mudstones have been converted by the igneous rock into black flinty hornstone or lydianite, the pore-space of which is practically nil.

In the table two columns of figures are given, the first of which represents the percentage weight of water absorbed, or the Ratio of Absorption,* the second being the percentage of the volume of the rock which can be occupied by the water imbibed; this is the percentage of pore-space or the Porosity. The porosity, as a matter of fact, is equal to the ratio of absorption multiplied by the specific gravity of the rock in question.

\section{Relation of Porosity to Geological Horizon.}

The sandstones by reason of their greater pore-space naturally form the most suitable criteria in the comparison of the relative porosity of successive geological horizons, and for this reason the majority of the

* E. R. Buckley. Wisconsin Geological and Natural History Survey, Bull. 4, Economic Series 2, p. 68, 1898. 
tests were made upon the sandstones, which, as a rule, are fine to medium-grained in texture and felspathic in character.

The basal member of the Karroo System in the Cape Province is the Dwyka conglomerate of glacial origin, a rather compact and somewhat impervious material; the Ecca shales which follow it are fine-grained with an average porosity not exceeding $2 \%$ very probably, except in the extreme south-west, where a sandy phase has been developed locally. These two formations crop out along the margin of the Karroo "basin," as shown on a geological map of the country. The Beaufort Series overlying the Ecca is characterized by the presence of sandstones and is the most important member of the Karroo System in South Africa in this investigation, inasmuch as it covers an area very much greater than that constituted by all the other series put together. Determinations of Beaufort rocks consequently preponderate in the table attached.

Even in the Beaufort Series the sandstones, which never possess more than a medium grain, do not predominate, for probably more than half of the strata consist of rather close-grained thinly bedded green and blue flaggy sandstones, hard nodular mudstones commonly somewhat gritty, and soft green, red, and purple clayey rocks, these bright-coloured layers being best developed in the upper portion of the formation.

The Beaufort Series has, partly upon lithological grounds, been subdivided into three groups, and in the table appended this three-fold classification has been developed, subject of course to such errors as may be brought in by uncertainty as to the exact geological horizon in any particular case. It has already been pointed out by Dr. C. F. Juritz* that underground waters of distinctive chemical character are furnished by each of these sub-divisions, and it can now be shown that the rocks of the three groups exhibit as well a variation in their capacity for absorbing water. Thus, for example, the sandstones of the Lower Beaufort Beds have a mean porosity of $2.9 \%$ (the average of 13 determinations, excluding No. 21, which was an uncommonly porous type of rock yielding a strong supply of water). By still further analysis it is found that sandstones coming from the higher horizons of this sub-division are more porous than those of the lower zones, the actual figures being $4.9 \%$ (4 determinations) as against $2.0 \%$ (9 determinations).

The Middle Beaufort sandstones are not so close-grained and furnish a value of $5 \cdot 2 \%$ (8 determinations), while the Upper Beaufort sandstones stand a trifle higher, $5.5 \%$ (14 determinations). The finer-grained rocks of the Upper Beaufort series are much more permeable than those of the Lower; the figures being $4.9 \%(5)$ and $1.4 \%$ (4) respectively.

* C. F. Juritz. Agric. Journ. of C.G.H., vols. xxxii. and xxxiii., 1908. Presidential Address to Cape Chemical Society, 1908. 
The Molteno sandstones of the Stormberg Series being coarser in grain and less compacted give a higher figure $10.9 \%$ (2), but more determinations are required to be made upon this formation and upon the finer-grained Cave Sandstone also.

It must be pointed out that, for the purpose of obtaining these figures, all samples taken from within 25 feet of the surface of the ground were rigidly excluded.

Proceeding from the Cape into the Transvaal, the Karroo System becomes thinner, this being partly due to the disappearance of certain zones represented in the Cape, namely the Ecca shales, and apparently the Molteno Series as well. At the same time the whole succession above the Dwyka becomes more arenaceous in character, and is now divisible into the Coal Measure grits and sandstones (probably representing some portion of the Beaufort Series), succeeded by the finer-grained Bushveld sandstone (apparently the equivalent of the upper part of the Stormberg Series).

The majority of the figures given for this section were determined upon samples of building stone obtained from quarries, and obviously the results, which are high, are not strictly comparable with those from the Cape, for the average porosity of three specimens of sandstone-core from the borings on the New Rand along the Wilge River in the Orange Free State is but $10.1 \%$ The Flatpan and Steenpan stone from the quarries near Coalbrook, Orange Free State, averages 12.1 \% (5 determinations), but the Vereeniging stone is much more porous, a specimen of medium-grained sandstone giving $18.3 \%$, while a very fine-grained white sandstone was remarkable in attaining the high value of $32.8 \%$.

The Coal Measure grits range from $8 \%$ to $18 \%$, but the Bushveld sandstone is less porous with values extending from $7 \%$ to $14 \%$, the red variety possessing a slight advantage in pore-space over the white.

The porosity of the Transvaal phase of the Karroo System, composed almost throughout of such arenaceous deposits, is therefore much higher than that of the Cape, but, since no bore-hole cores of the former have yet been experimented upon, the water-bearing capacities of the two phases cannot satisfactorily be compared at present.

\section{Relation of Porosity to Specific Gravity.}

Since the more compact rocks possess a higher density than the more open-grained ones, it follows that the value of the porosity of a sample must approximately be inversely proportional to its specific gravity. In the following figure these two quantities have been plotted in the case of 90 rocks, and it will be seen that the porosities fall within well-defined limits, showing that, in dealing with samples having a given density, the 
pore-space lies between maximum and minimum values. Excepting in the case of one of the Vereeniging sandstones the maximum porosity reached falls far short of the theoretical minimum of $26 \%$ for a rock composed of uniform grains packed in the closest manner possible; * the discrepancy

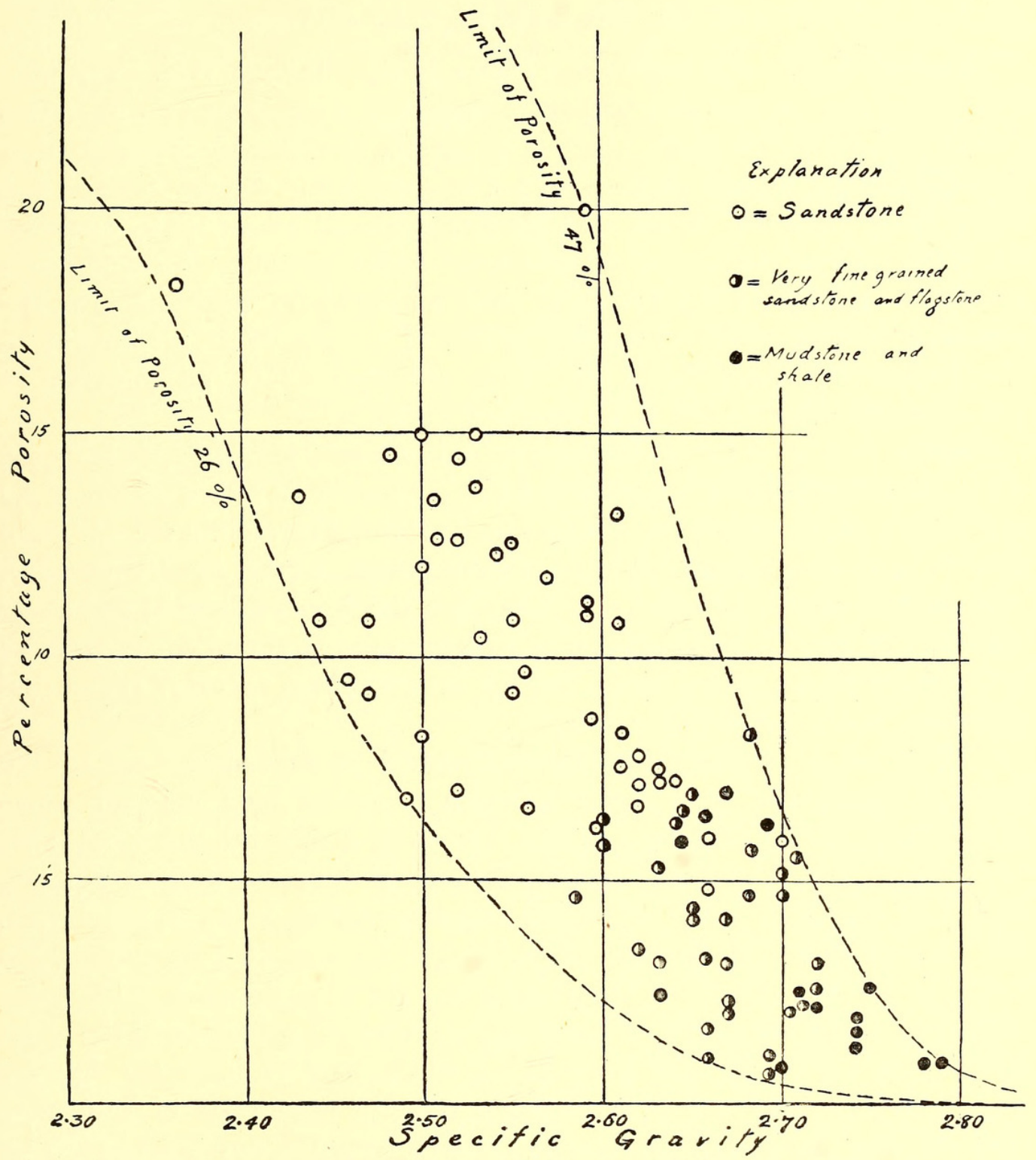

Diagram showing Dependence of Porosity on Specific Gravity.

is obviously due to the presence of particles much smaller than the average and to finely divided matter partially filling the pores.

Decrease in density beyond the limits here plotted means that the samples have become more open in texture and less coherent by loss of

* C. S. Slichter. Nineteenth Ann. Rept. United States Geological Survey, part 2, p. $310,1899$. 
the cementing matter. Beyond this stage thoroughly decomposed rocks would have to be included, and after that the soils produced by them; the consideration of these is outside the scope of this paper, however.

\section{Effect of Weathering upon Porosity.}

Most of the Karroo sandstones (those of the Molteno Beds excepted), and not a few mudstones, possess a cement of a calcareous nature ; this forms generally not more than $2 \%$ of the weight of the rock, but occasionally the proportion rises to $4 \%$ or even $5 \%$. At the surface and down to a moderate depth this binding material tends to be removed by water containing dissolved carbonic acid; usually the calcareous matter is ultimately conveyed by the underground drainage into the rivers, but sometimes under the action of capillarity it is brought to the surface and there forms the white calcareous tufa, so common in the northern Karroo and the Orange Free State.

Again, nearly all the sandstones contain a moderate amount of felspar, which in the process of weathering becomes converted into a porous mass of kaolin; at the very outcrop also the finely divided kaolin "dust" will tend to be removed mechanically. Other minerals, such as sericite, mica, and chlorite, together with substances the exact mineralogical nature of which is uncertain, are also present as a ground-mass, and some of these must undergo alteration with partial or complete removal under the chemical action of ground-water.

An attempt to determine the proportion of calcareous cement by soaking specimens in a weak solution of citric acid did not prove satisfactory, so recourse was had to a treatment with dilute hydrochloric acid, by which, however, certain silicates of alumina and to a lesser extent of magnesia were broken up and removed as well. It is believed, for reasons that will become self-evident further on, that in spite of the severity of this treatment the results are quite comparable with those produced under the action of the weather; that the processes of the latter sometimes results in the solution of silicic acid is indicated by the extremely incoherent nature of some outcrop specimens of sandstone and by the secondary silicification which appears now and again on rock surfaces or in certain superficial deposits in South Africa.

As an example, five specimens of sandstone lost on an average $2.0 \%$ of their weight by soaking in acid, this figure corresponding to an increase in pore-space of about the same amount; the actual increases in porosity ranged from about $\frac{1}{15}$ th to $\frac{3}{4}$ ths of those in the untreated rocks, while the average increase was nearly $\frac{1}{3} \mathrm{rd}$.

In the instances under discussion the percentage increase in porosity due to the removal of cementing matter ranged between 2 and 14 times 
the percentage decrease in weight of the rock during treatment. Some of the material extracted by the dilute hydrochloric acid (and therefore present in the form of chlorides of the bases along with silicic acid) was evaporated to dryness, and the residue, when examined chemically, was found to have the following composition (the bases being reckoned as oxides) : silica, $33 \%$; oxides of alumina and iron, $24 \%$; lime, $26 \%$; and magnesia, $10 \cdot 8 \%$.

Comparing the figures obtained for the porosities of samples taken from the surface, or immediately below the surface, with those of specimens from greater depths, the average values for the Beaufort Series work out as follows :-

Lower Beaufort, weathered, $5 \cdot 1 \%$ (3 determinations)

Lower Beaufort, unweathered, $2.9 \%$ (13 determinations)

Middle Beaufort, weathered, $5 \cdot 6 \%$ (2 determinations)

Middle Beaufort, unweathered, $5 \cdot 2 \%$ (8 determinations)

Upper Beaufort, weathered, $9 \cdot 7 \%$ (4 determinations)

Upper Beaufort, unweathered, $5.5 \%$ (14 determinations)

It is thus seen that substantial increases in porosity have been brought about within the surface zone; incidentally this fact should form a very strong argument in favour of deep quarrying for the supply of durable building stone, a matter which has consistently been ignored throughout South Africa.

\section{Relation of Porosity to Water Storage.}

When the figures for the Karroo rocks are compared with those for sandstones in other countries, * it is found that the South African rocks as a whole possess quite a low degree of porosity, the Lower Beaufort Beds being most marked in this respect; only the Transvaal Coal Measures can be regarded as being moderately porous.

The actual capacity of a stratum for storing water is fortunately, however, not the same thing as its porosity, for, in addition to the capillary passages between the constituent grains, there are numerous minute cracks and joints which traverse the rock in various directions, most frequently in planes at right angles to the stratification.

Such cracks and joints are most numerous and widest as a rule at the surface of the ground, and they become of less importance with depth; generally below the 400-foot level the capacity of the rock does not differ much from its porosity. Above that level the capacity is much greater, and in the uppermost zone it may greatly exceed the value found for the pore space, especially if the porosity of the rock be low.

* E. R. Buckley, l.c., p. 400. O. Lueger. Die Wasserversorgung der Städte, pp. 217-19, Stuttgart. 
It is for these reasons that the close-grained Lower Beaufort Beds yield supplies which in many places seem extravagantly in excess of what would be expected from the closeness in grain of the individual beds. It follows that the supplies to be obtained from such formations will be drawn principally from the surface zones within which fissures and joints exist, and deep borings will generally not be more advantageous.

The results of boring in the Karroo entirely support these contentions, for it must be noted that the numerous dolerite intrusions cutting through the strata cause the shallow ground-waters to become concentrated at certain points and thus enable wells to be sunk at such spots with success.

\section{Permeability of Strata.}

It is very unfortunate that all the experiments upon the permeability of sandstones have been carried out upon varieties possessing a porosity of over $15 \%$, usually a much higher value. The rate of flow of water under pressure through such weakly permeable sandstones as those of the Beaufort Beds of the Cape Province is therefore quite uncertain, though, from the rapid falling off of permeability with diminution of porosity as shown in other more open-grained sandstones, the figures would appear to be very low for the formation in question.

As regards the Transvaal, the figures given in the table apply to material from quarries only, and it is likely, judging from analogy with the data available from the Cape, that the porosity in depth of the Coal Measure grits and sandstones will range most probably from about $5 \%$ to $12 \%$.

Experiments like those carried out by Baldwin-Wiseman * upon the rate of flow of water under varying pressures through unweathered blocks of such sandstones, are much to be desired, because in the Transvaal these rocks in a number of places occupy gentle depressions in the older impervious formations, they are invaded by dolerite to a limited degree only, and they crop out in regions of fairly good rainfall.

The question of the permeability of these sandstones is therefore an important one in view of possible deep boring in certain localities. It is to be hoped that in the near future determinations may be made of the permeability of the sandstones of the Karroo System, a representative set being selected which will cover the wide range in porosity possessed by the various types as brought out in the following tables.

With such data secured, many problems of underground water supply could then be attacked with more hope of success. Upon the results obtained the policy of deep boring would perforce be based, while the ideas of boring engineers upon this subject would necessarily become less nebulous, and the scope of their operations more extended.

* Min. and Proc. Inst. Civil Engineers, vol clxv., part 3, 1906. 
Porosity of the Rocks of the Karroo System.

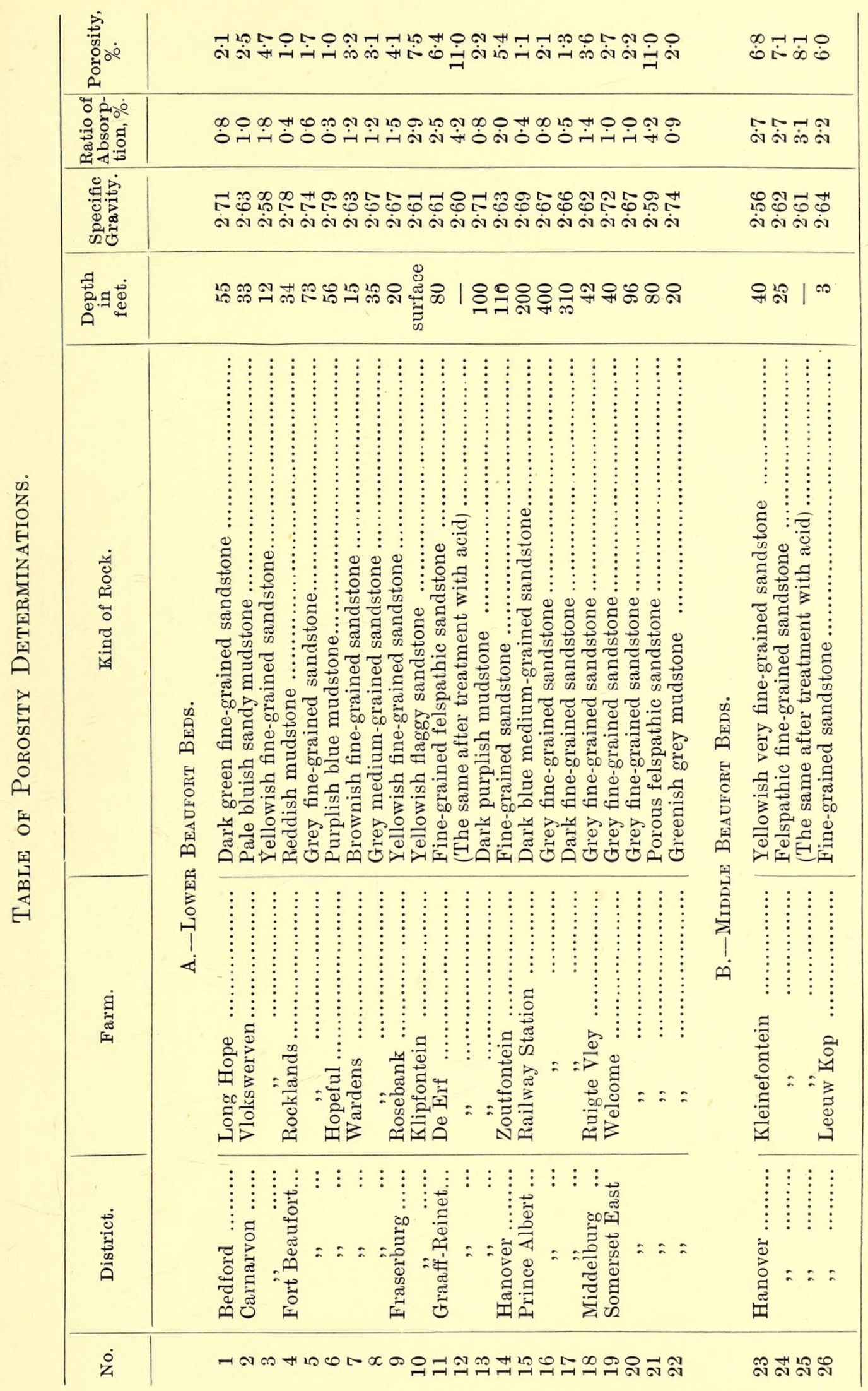




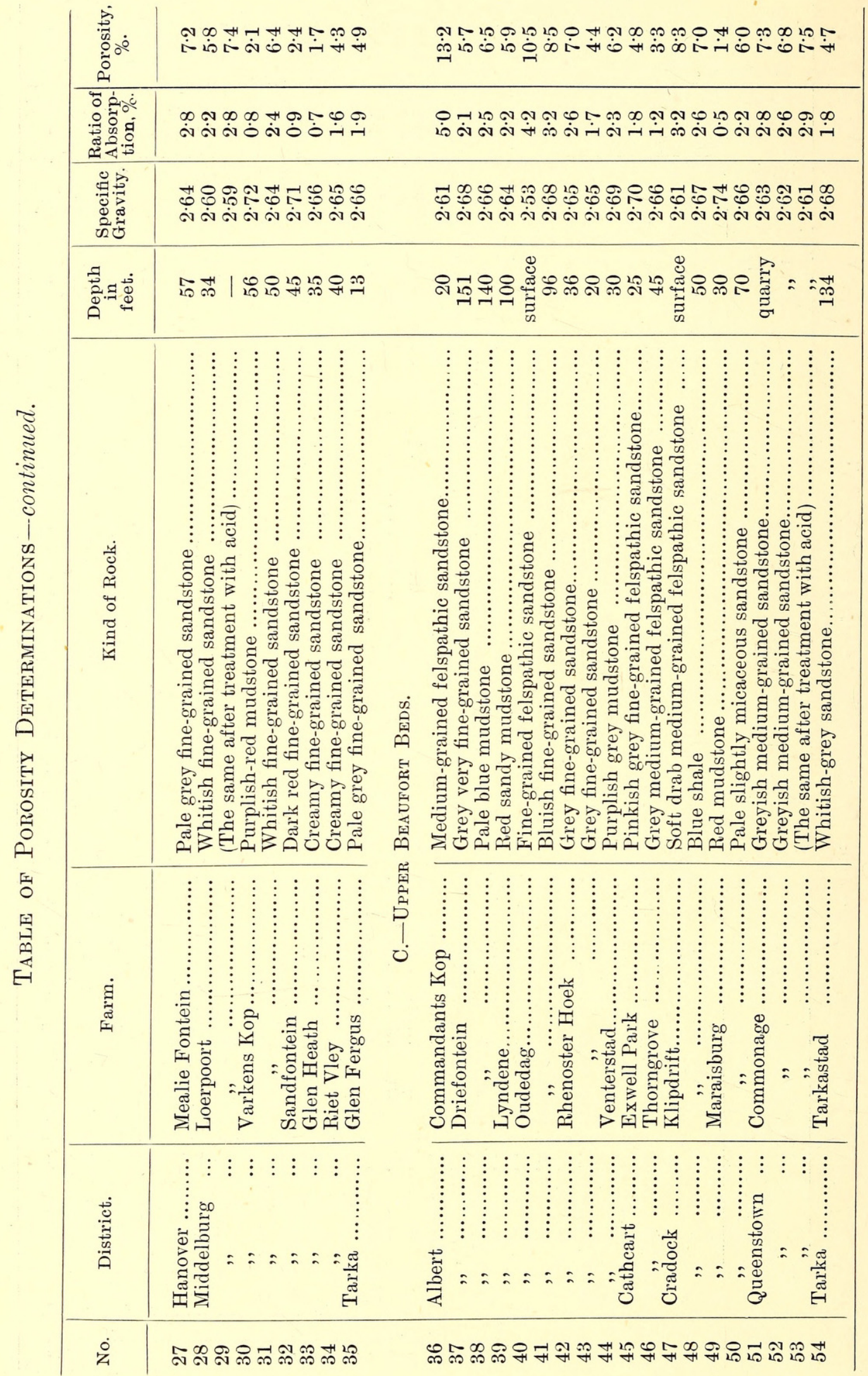


Porosity of the Rocks of the Karroo System.

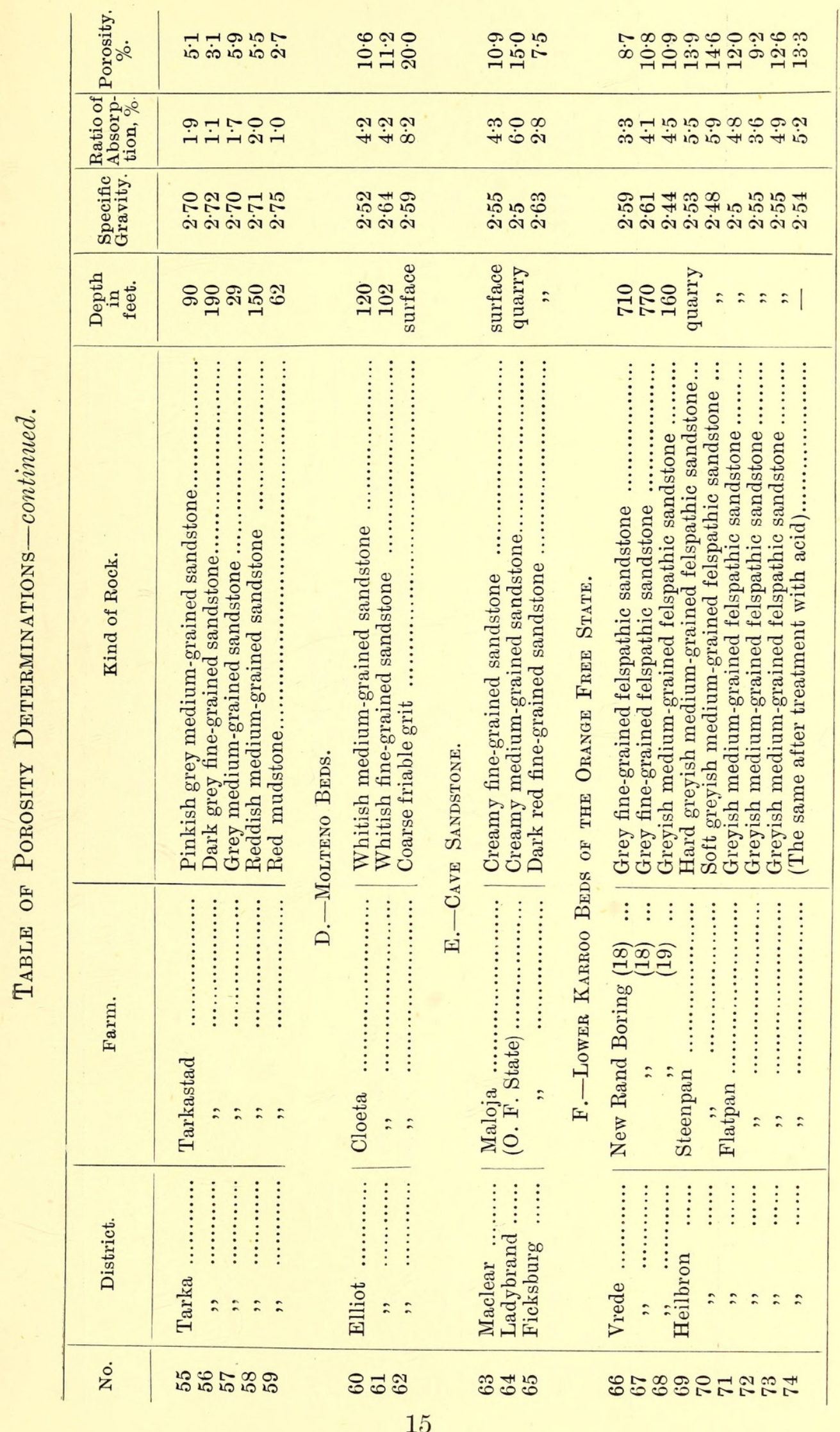




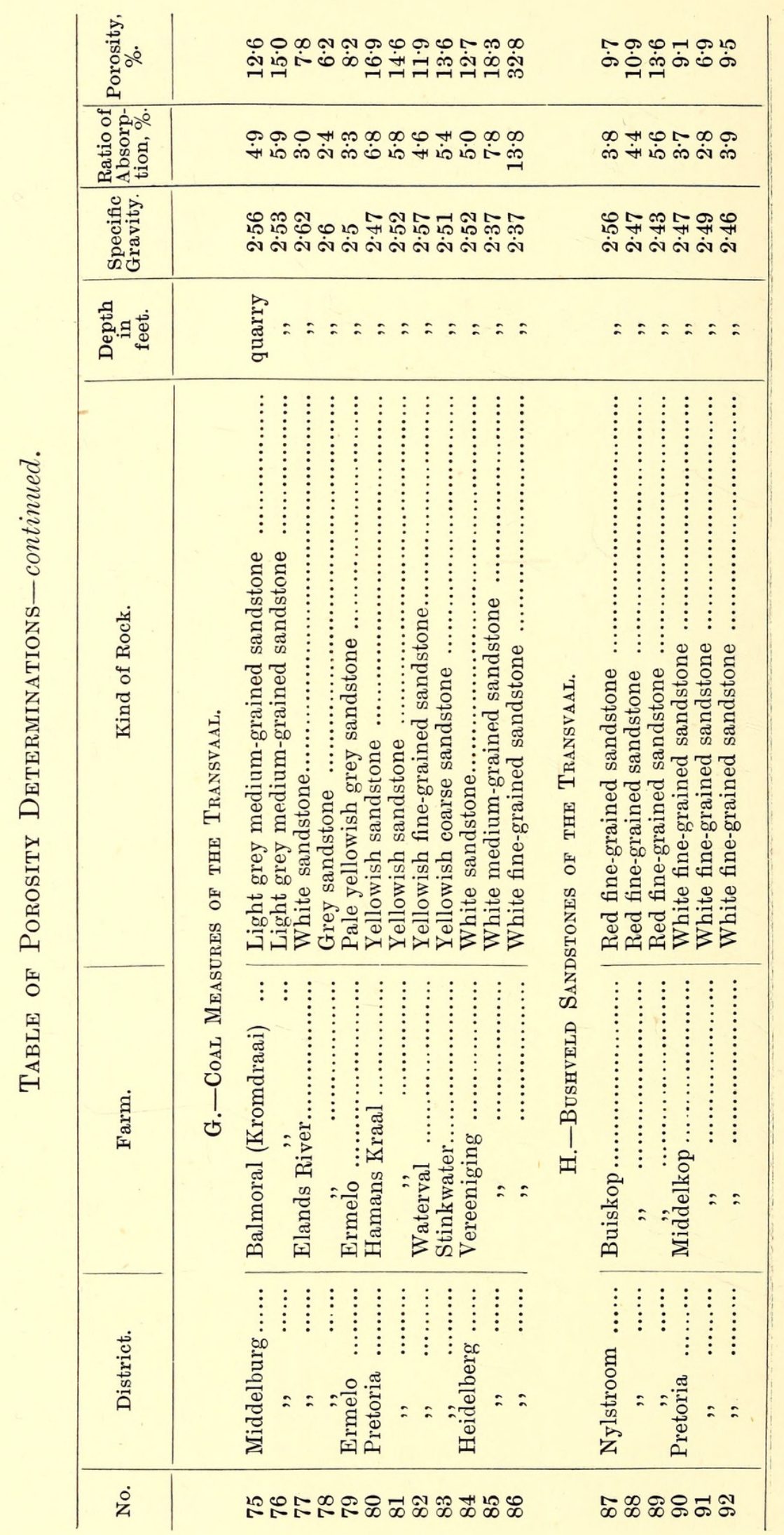




\section{$2 \mathrm{BHL}$ Biodiversity Heritage Library}

Du Toit, Alex. L. 1914. "ON THE POROSITY OF THE ROCKS OF THE KARROO SYSTEM IN SOUTH AFRICA." Transactions of the Royal Society of South Africa 4, 169-180. https://doi.org/10.1080/00359191409519529.

View This Item Online: https://www.biodiversitylibrary.org/item/181590

DOI: https://doi.org/10.1080/00359191409519529

Permalink: https://www.biodiversitylibrary.org/partpdf/175535

\section{Holding Institution}

Smithsonian Libraries

\section{Sponsored by}

Biodiversity Heritage Library

\section{Copyright \& Reuse}

Copyright Status: Not in copyright. The BHL knows of no copyright restrictions on this item.

This document was created from content at the Biodiversity Heritage Library, the world's largest open access digital library for biodiversity literature and archives. Visit BHL at https://www.biodiversitylibrary.org. 